\title{
EXPLORING THE RELATIONSHIP AMONG PLANNING RELIABILITY (PPC), LINGUISTIC ACTION INDICATORS AND SOCIAL NETWORK METRICS
}

\author{
Fabián Retamal ${ }^{1}$, Luis A. Salazar ${ }^{2}$, Rodrigo F. Herrera ${ }^{3}$, and Luis F. Alarcón ${ }^{44}$
}

\begin{abstract}
Research has demonstrated the importance of information flow and workflow in the architecture, engineering and construction (AEC) industry. Through the correct application of the Last Planner ${ }^{\circledR}$ System, the coordination of a project and therefore its workflow has been improved. However, there is still a productivity gap that must be addressed through proper commitment management and good communication. Therefore, the objective of this article is to explore the relationship among planning reliabilityusing percentage plan completed (PPC) measures - linguistic action perspective (LAP) indicators and social network analysis (SNA) metrics in four construction projects that use the Last Planner ${ }^{\circledR}$ System in Chile and Colombia. A future line of research will be to analyze this relationship in conjunction with the main reliability indicators of construction projects through the application of PPC, LAP and SNA in more case studies.
\end{abstract}

\section{KEYWORDS}

Linguistic Action Perspective, Last Planner ${ }^{\circledR}$ System, Social Network Analysis, Percentage Plan Completed, Case studies

\section{INTRODUCTION}

In the architecture, engineering and construction (AEC) industry, the importance of information flow and workflow is well understood (Alarcón et al. 2013). Specifically, in construction execution, information flow in projects that use the Last Planner ${ }^{\circledR}$ System is crucial during weekly work planning (WWP) meetings because communication improves project coordination and thus its workflow (Priven and Sacks 2015).

In WWP meetings, information flow is based on interactions among participants. The work team creates communication, coordination and collaboration activities to execute

1 MSc Student, Department of Construction Engineering and Management, Pontificia Universidad Católica de Chile, Researcher - GEPUC, Santiago, Chile, +56 22354 7165, faretamal@uc.cl, orcid.org/0000-0002-6554-5576

2 PhD Candidate, Department of Construction Engineering and Management, Pontificia Universidad Católica de Chile, Professor, Construction Engineering, Faculty of Engineering, Universidad Andres Bello, Santiago, Chile, +56 22661 8346, lasalaza@,uc.cl, orcid.org/0000-0001-7339-8935

3 PhD Candidate, Department of Construction Engineering and Management, Pontificia Universidad Católica de Chile, Professor, School of Civil Engineering, Pontificia Universidad Católica de Valparaíso, Chile, +56 94413 2109, rodrigo.herrera@pucv.cl, orcid.org/0000-0001-5186-3154

4 Professor, Department of Construction Engineering and Management, Pontificia Universidad Católica de Chile, Santiago, Chile, +56 2354 7165, lalarcon@ing.puc.cl, orcid.org/0000-0002-9277-2272 
the workplan for the next week (Schöttle et al. 2014). Therefore, deficient information flow within work teams can create poor performance in the lifecycle of projects (Baiden et al. 2006).

Project management theory assumes that the predecessor activities and the resources required to execute these tasks are always available. However, this is not always the case (Koskela and Howell 2002b). It is incorrect to assume that the task will be fully understood, initiated and completed as planned, even considering workers' commitment to their important jobs (Koskela and Howell 2002b).

According to Helmreich (1998), success in organizational management is achieved through trust, nonpunitive policies, commitments, and addressing different types of errors, among other actions. According to the above, the Last Planner ${ }^{\circledR}$ System and communication can improve productivity through commitment management, increasing the reliability of planning and improving the level of project performance (Ballard, 1994).

The aim of this paper is to understand the relationship among planning reliability in project performance - using percentage plan completed (PPC) measures - indicators of the linguistic action perspective (LAP) and social network analysis (SNA) metrics in four construction projects that use the Last Planner ${ }^{\circledR}$ System in Chile and Colombia.

\section{BACKGROUND}

\section{Linguistic ACtion Perspective}

In practice, tasks are generally assumed to be fully understood by the team member who must do the work. However, the tasks cannot be completed without considering the worker's importance as the executor of those tasks (Salazar et al. 2018). Therefore, it is important to propose the linguistic action perspective in projects due to the effectiveness of commitments in the Last Planner® System (Howell et al. 2004).

"Conversations for action" are interactions between participants with the purpose of coordinating different actions in any meeting (Salazar et al., 2018). Therefore, Flores (2015) defines four stages of a conversation for action, which is strongly related to commitments defined as a chain of commitments. The four stages are as follows: (1) preparation for a request; (2) negotiation and agreements; (3) execution and declaration of compliance; and (4) acceptance and declaration of satisfaction.

To measure the four stages, Salazar et al. (2018) proposed indicators that were validated in case studies in Chile during 2019 (Salazar et al. 2019). During these studies, contractors were consulted about their perceptions and agreed on the importance of providing reliable promises in conversations for action to manage commitments.

The authors developed this research from the study of the AEC industry and these previously proposed metrics. To apply these metrics, our work must complement the analysis of social networks. Diehl (2019) provides a more empirical approach to the analysis of social networks, emphasize the content of network ties and contribute to a more direct study of the interaction patterns under the linguistic action perspective.

\section{SOCIAL NeTWORK ANALYSIS}

A project team with more interactions may generate better performance due to its ability to generate high levels of commitment and trust between participants (Phelps 2012). These interactions may be represented by a network of commitments among its members who seek to achieve the aims of the project (Viana et al. 2011). One way to measure real connections between people is using social network analysis (SNA). This analysis 
includes the structure of social relationships as well as formal and even informal connections (Alarcón et al. 2013).

The use of social network analysis in the AEC industry provides evidence of evaluations of traditional interaction dimensions in this industry, such as personal interactions, information flow, planning, problem solving, collaboration, trust and learning (Herrera et al. 2020). In these networks, each member of the work team is represented by a node, and the connection between two nodes represents the connection (e.g., communication, commitment, trust) that has occurred (Alarcón et al. 2013). In addition, from the perspective of commitments in linguistic action perspective and social network analysis, these metrics can be reflected by shared understanding in weekly meetings.

\section{SHARED UNDERSTANDING}

Normally, people only share information when it is necessary. In project teams, each person knows her or his role and participates in a knowledge system in which not everyone knows everything, and they must to succeed in a project, so they need to communicate (Kleinsmann et al. 2012). It is assumed that in any type of communication, a shared understanding is required. Shared understanding is a key measure of communication effectiveness in work teams (Humayun and Gang 2013). In addition, when team members execute a collaborative approach, it is accompanied by a systematic discussion and negotiation, and it is particularly important to use a shared understanding to make agreements among team members and to develop a commitment management approach, reflecting the linguistic action perspective. (Cash et al. 2017; Kleinsmann et al. 2012; Viana et al. 2011).

Furthermore, it is possible to use SNA for collaboration and evaluation in construction project teams (Kereri and Harper 2019). Additionally, in construction work teams, there is evidence of commitment management (Herrera et al. 2020), which can be measured using the four stages of the conversation for actions. Then, it is important to comprehend the shared understanding process in teams that are multidisciplinary, in which negotiations and discussions are common (Kleinsmann et al. 2012).

\section{RESEARCH METHODOLOGY}

The case study methodology was selected due to the type of research questions (how and why) and because researchers lack control over events and contemporary phenomena (Yin 2003). A controlled experiment was dismissed because the study does not represent a "sample", as an experiment does. A longitudinal-multiple-holistic case study was established because this research aims to extend and conceptualize theories through an analytical generalization of causal relationships (simple and complex), verifying whether the study cases support the proposed theory (Yin, 2003) and are not a statistical generalization, both of which are epistemologically independent (Yacuzzi 2005; Yin 2003).

Information-oriented selection was used due to the feasibility of research with companies belonging to the Engineering and Construction Management Research Group (INGECO - Colombia) and Collaborative Group of the Center of Excellence in Production Management (GEPUC - Chile). The research concerns four cases, which are located in Santiago, Chile (two projects) and Bogotá, Colombia (two projects), with similar characteristics, such as implementation of the Last Planner ${ }^{\circledR}$ System in their projects and tall building projects. Then, extreme or deviant cases were established by 
selecting atypical projects in each company because our goal was to obtain information on cases that were especially problematic or anomalous in one respect (Flyvbjerg 2006). Finally, the "location dimension" was used to compare differences and similarities among the projects in Chile and Colombia because it is possible to measure the cultural impact of people and organizations in commitment management and the general performance of projects.

The metrics were selected according to the state of the art for LAP (Salazar et al. 2018; Salazar et al. 2019) and SNA (Herrera et al. 2020). The method proposed by Herrera et al. (2020) was used to evaluate social networks because it includes a commitment management perspective. To analyze the project meetings, authorization was requested from each of the attendees through informed consent, detailing the purposes of the investigation, ensuring the confidentiality of names and making known the treatment of the data collected.

At least one researcher attended each of the meetings to inform the rest of the research team of their personal observations regarding the mood and general aspects of the meeting. The investigator in charge also had the function of recording each entire meeting with a $360^{\circ}$ camera. The team then reviewed the video recordings and recorded the LAP indicators according to Salazar et al. (2018 and 2019). The SNA indicators were measured through the application of the survey developed by Herrera et al. (2020). Taking advantage of the fact that the work team of each project was colocated, the SNA survey was applied to each project physically at the last LPS meeting that the researchers attended. The average estimated duration of the meetings was one and a half hours, though there was great variability, with the shortest meeting ending in 40 minutes and the longest one lasting 3 hours.

\section{RESEARCH TASKS}

The performance steps were as follows:

1. Surveys and indicator selection: Current indicators created and validated previously by the authors were used, such as social network surveys (Herrera et al. 2020) and the LAP checklist (Salazar et al. 2018 and 2019), to analyze the attendees of WWP meetings.

2. Instruments application: For four weeks, WWP meetings were analyzed to determine the LAP indicators, following the methodology proposed by Salazar et al. (2018), and a social network survey proposed by Herrera et al. (2020) was conducted to determine interactions between participants. The metrics used are as shown in Table 1.

3. Results validations: The LAP results were validated by the authors through video recordings of WWP meetings and the double-blind method of the network survey.

4. Analysis of results: The researchers analyzed the differences between the two countries regarding sociocultural conditions in project management. Additionally, this paper analyzed the relationship among percentage plan completed (PPC) measures, LAP indicators and SNA metrics. This is an approach for conducting future research with more projects.

5. Discussion and conclusions: The authors applied cause-and-effect analysis of each dataset collected. 
Table 1: Networks and metrics evaluated

Source: Own elaboration, based on Herrera et al. (2020)

\begin{tabular}{|c|c|c|}
\hline Network & Metric & Description \\
\hline $\begin{array}{l}\text { Knowledge of roles and } \\
\text { responsibilities }\end{array}$ & Density & $\begin{array}{l}\text { Ratio between the number of actual knowledge of roles links } \\
\text { existing between nodes and the number of total possible links in } \\
\text { the network. }\end{array}$ \\
\hline Collaboration & Density & $\begin{array}{l}\text { Ratio between the number of validated collaboration links } \\
\text { (bidirectional connection) and the number of total possible links } \\
\text { in the network. }\end{array}$ \\
\hline $\begin{array}{l}\text { Planning and problem } \\
\text { solving }\end{array}$ & Density & $\begin{array}{l}\text { Ratio between the number of validated planning and problem- } \\
\text { solving links (bidirectional connection) and the number of total } \\
\text { possible links in the network. }\end{array}$ \\
\hline Learning & Density & $\begin{array}{l}\text { Ratio between the number of actual learning links existing } \\
\text { between nodes and the number of total possible links in the } \\
\text { network. }\end{array}$ \\
\hline Trust & Trust index & $\begin{array}{l}\text { Ratio between the number of trust links and the number of } \\
\text { knowledge of roles links. }\end{array}$ \\
\hline $\begin{array}{l}\text { Requirement } \\
\text { negotiation }\end{array}$ & $\begin{array}{l}\text { Negotiation } \\
\text { index }\end{array}$ & $\begin{array}{l}\text { Ratio between the number of validated negotiation links } \\
\text { (bidirectional connection) and the number of links in which a } \\
\text { requirement is realized. }\end{array}$ \\
\hline
\end{tabular}

\section{CASE STUDIES}

Four projects with the same characteristics (including tall building type) were measured. Two projects were measured in Santiago, Chile, Project A and Project B. Project A was measured between April $30^{\text {th }}$ and June $11^{\text {th }}$ during four nonconsecutive weeks, while Project B was measured between May $8^{\text {th }}$ and June $5^{\text {th }}$ in four consecutive weeks. Two projects were also measured in Bogota, Colombia, Project $\mathrm{C}$ and Project D. Project $\mathrm{C}$ was measured between October $1^{\text {st }}$ and October $29^{\text {th }}$, while Project D was measured between September $30^{\text {th }}$ and October $28^{\text {th }}$ during four nonconsecutive weeks. Table 2 shows the PPC of these four projects with the week of measurement.

Table 2: Percentage Plan Completed (PPC) Source: Own elaboration

\begin{tabular}{lllll}
\hline Project & \multicolumn{4}{l}{ Percentage Plan Completed (\%) } \\
\hline & Week 1 & Week 2 & Week 3 & Week 4 \\
\hline A & 71.79 & 78.95 & 71.43 & 70.59 \\
B & 35.71 & 52.94 & 50.00 & 30.77 \\
C & 69.39 & 84.35 & 54.93 & 73.24 \\
D & 67.22 & 67.60 & 69.29 & 69.29 \\
\hline
\end{tabular}

In addition, the linguistic action perspective results are shown in Table 3 . The average of each indicator was calculated and divided into positive actions of the LAP ("+" on Table 3) and negative actions ("-" on Table 3), according to what was established in Salazar et 
al. (2018). Then, the average of the positive LAP (+) and negative LAP (-) indicators was created, as shown in Table 4.

Table 3: Average Linguistic Action Perspective (LAP) indicators in percentage

Source: Own elaboration

\begin{tabular}{lllll}
\hline LAP indicator (\%) & \multicolumn{3}{l}{ Project } & \\
\cline { 2 - 5 } & A & B & C & D \\
\hline Arrives on time (+) & 63.4 & 65.53 & 87.85 & 63.18 \\
\cline { 2 - 6 } Take notes (+) & 64.25 & 44.35 & 38.48 & 30.98 \\
\cline { 2 - 5 } Check mobile phone (-) & 1.48 & 9.48 & 14.95 & 31.60 \\
\cline { 2 - 6 } Mobile phone rings (-) & 1.33 & 4.38 & 15.20 & 12.48 \\
\cline { 2 - 6 } Talk by mobile phone (-) & 0.00 & 2.33 & 5.05 & 10.08 \\
\cline { 2 - 6 } Leave the room (-) & 5.43 & 10.15 & 4.90 & 7.23 \\
Walkie talkie rings (-) & 1.33 & 0.00 & 0.00 & 1.43 \\
Talk by walkie talkie (-) & 1.33 & 0.00 & 0.00 & 0.00 \\
Does not speak in meeting (-) & 13.35 & 30.58 & 16.23 & 19.70 \\
Does not look at the person who is speaking (-) & 0.00 & 3.75 & 0.00 & 1.58 \\
\hline
\end{tabular}

Table 4: Positive and negative Linguistic Action Perspective indicators Source: Own elaboration

\begin{tabular}{lll}
\hline Project & $\begin{array}{l}\text { Positive LAP (+) } \\
(\%)\end{array}$ & $\begin{array}{l}\text { Negative LAP (-) } \\
(\%)\end{array}$ \\
\hline A & 63.83 & 3.03 \\
B & 54.94 & 7.58 \\
C & 63.16 & 7.04 \\
D & 47.08 & 10.51 \\
\hline
\end{tabular}

Once the indicators were taken, they were compared with the social network analysis (SNA) metrics. This analysis was performed to define roles, planning, trust, learning and negotiation with the corresponding metrics: density in knowledge of roles, planning, collaboration and learning. As part of this effort, the negotiation index and trust index were determined. Table 5 presents all the SNA metrics. 
Table 5: SNA metrics

\begin{tabular}{lllllll}
\hline Project & $\begin{array}{l}\text { Role } \\
\text { knowledge } \\
\text { density }\end{array}$ & $\begin{array}{l}\text { Planning } \\
\text { network } \\
\text { density }\end{array}$ & $\begin{array}{l}\text { Collaboration } \\
\text { density }\end{array}$ & $\begin{array}{l}\text { Trust } \\
\text { indicator }\end{array}$ & $\begin{array}{l}\text { Learning } \\
\text { density }\end{array}$ & $\begin{array}{l}\text { Negotiation } \\
\text { indicator }\end{array}$ \\
\hline A & $68 \%$ & $19 \%$ & $23 \%$ & $47 \%$ & $23 \%$ & $68 \%$ \\
B & $71 \%$ & $54 \%$ & $31 \%$ & $58 \%$ & $47 \%$ & $59 \%$ \\
C & $43 \%$ & $13 \%$ & $9 \%$ & $71 \%$ & $26 \%$ & $41 \%$ \\
D & $28 \%$ & $8 \%$ & $6 \%$ & $54 \%$ & $13 \%$ & $39 \%$ \\
\hline
\end{tabular}

\section{ANALYSIS OF THE RESULTS}

To analyze the results, an information crossover between the analysis of social networks with the positive and negative indicators of language action was used. Figure 1 shows an example of how the data were crossed for each of the SNA metrics (percentage of each project), where the $\mathrm{X}$ axis and $\mathrm{Y}$ axis correspond to the positive and negative indicators of linguistic action, respectively. This crossover of information was used for each SNA metric.

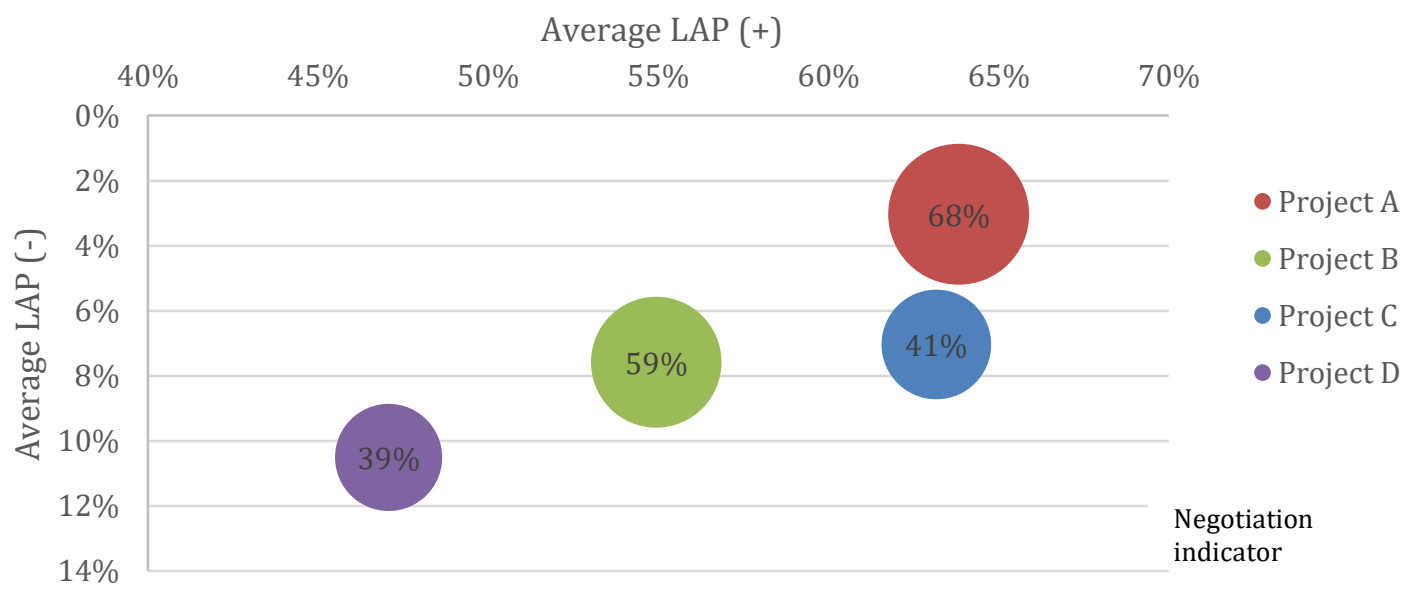

Figure 1: SNA vs LAP diagrams, Negotiation indicator. Source: Own elaboration

Project D (from Colombia) has the worst percentage in LAP metrics, while Project A (from Chile) has the best LAP indicators. Furthermore, in PPC, Project B (from Chile) has the worst PPC indicators in the four weeks that were measured and demonstrates unusual behavior in the relationship between the SNA metrics and LAP indicators. Regarding knowledge of roles, the Colombian project teams have low percentages, with $43 \%$ and $28 \%$ in Projects $\mathrm{C}$ and $\mathrm{D}$, respectively. The Chilean project teams have better knowledge of roles and, in consequence, have better performance in all the SNA metrics.

In WWP, Project B shows a peculiar behavior in the SNA metrics because there are many interactions (54\%), but its PPC is the poorest. The authors watched videos about its meetings again, and they noticed that these weekly meetings were deficient because only technical aspects were discussed, such that there were many interactions, but they were not about weekly planning. Although problems were solved, they were only solved in 
technical aspects. Perhaps in these excessive interactions, a disorder was generated in the negative LAP since it is not proven that more interactions are related to better planning (Herrera et al., 2020), and in fact, more interactions can cause deficiency problems, as seen in the PPC evolution (35.71\% - 52.94\% - 50.00\% - 30.77\%). Meanwhile, Projects $\mathrm{A}, \mathrm{C}$ and $\mathrm{D}$ have low interactions in weekly planning, and they have better performance in PPC. Again, the Chilean projects have better planning reliability than the Colombian projects in this SNA metric.

In collaboration, Project B shows the same unusual behavior. As with the previous metric, 31\% collaboration is not excessive. Since the Project B team only discusses technical aspects, it will have high collaboration exclusively in those aspects according to the videos and its poor PPC. Project A, on the other hand, has more collaboration than planning because, according to the weekly meetings and videos, people talk about more aspects than is necessary in these meetings. In addition, the Colombian projects have lower collaboration than the Chilean projects, as was reflected in the previous SNA metrics.

The trust indicator does not concern density as the previous metrics do. This indicator is the number of links of trust in relation to the people who know their role, not to the total possible project members. People in the Colombian projects know fewer people than people in the Chilean projects do, and the people on the Colombian teams trust their peers less than the Chilean team members do. Additionally, Colombian workers do not know their peers' roles. In the Chilean projects, people know their peers better, and the trust indicator in average is lower than that of the Colombian projects because of this. Therefore, it is important to show that the SNA metrics in the Chilean projects are better than those in the Colombian projects in all aspects because this indicator (trust) reveals the trust that team members generate when requesting different tasks and how they make these requests, avoiding the organizational structure and being more direct in requesting and delivering information among their peers.

As there is greater collaboration and planning in project $\mathrm{B}$, the team establishes greater learning regarding that project, although as mentioned above, they only learn about the technical aspects from each other. On the other hand, Projects A and $\mathrm{C}$ have better LAP indicators and, consequently, have similar behaviors. Additionally, these two projects have better PPC (on average) than the other two projects.

The last metric of SNA that was measured is the negotiation indicator. This indicator is bidirectional; it is a negotiation between two people who interacted and has a fundamental role in the linguistic action perspective. As shown in Figure 1, when better LAP indicators exist, better SNA metrics and better PPC are also observed. The only rare case is Project B, which is based on a low PPC and the argument regarding the previous points about discussions being limited to the technical aspects. Furthermore, according to the videos, Project D had never identified project delays, and as a consequence, there was never negotiation in the WWP and the team had a poor PPC.

\section{CONCLUSIONS}

In the four projects that were measured during the research, the Colombian projects had lower interactions between and knowledge about their peers. This problem lies in the cultural impact that each country has. Additionally, it is important to show that Colombian culture is more respectful than Chilean culture; ergo, the relationship between peers is more stratified in Colombia than in Chile. In future studies, the importance of culture in the relationship between project planning reliability and weekly meeting planning must 
be investigated in depth, and the linguistic action perspective is a likely approach for this future research.

Project A is the best project that was measured: the PPC, LAP indicators and SNA metrics are higher than those of the rest of the projects. On the other hand, Project B has the worst PPC and good SNA metrics because they talked in weekly planning meetings about technical aspects exclusively. In the rest of the projects, the SNA metrics and LAP indicators are better as reliability increases. Project $\mathrm{C}$ has good Last Planner ${ }^{\circledR}$ implementation. However, its execution is not high because they have problems about personal declared performance. There was no communication, and they did not know each other, which hindered the interactions with their peers.

The relationship between the negotiation index and LAP indicators is strong but requires more projects to attain a representative sample. This paper is a step toward future research on the relationship among these three global indicators. It is important to show that every project has different problems in every meeting. Therefore, it is important to know the contextualization of each of the projects by directly attending these planning meetings. Data are not meaningful if researchers work alone without knowing the context because statements may be made that are incorrect.

The information and visualization of videos contribute greatly to authors' ability to find improvements or shortcomings in a given meeting and verify them with the indicators of SNA and linguistic action objectively. Therefore, improvements are generated in the flow of information and communication on the different requirements that arise in each meeting, making the team more effective and efficient as it seeks to reach reliable commitments. In future research, the authors argue that a better metric can be found for how language action indicators are visualized to avoid the conflict between positive and negative indicators.

\section{ACKNOWLEDGMENTS}

We thank GEPUC and INGECO for their support in this research. Additionally, Luis A. Salazar acknowledges the financial support for his PhD studies from the Scholarship Programme of Conicyt Chile (ANID-PCHA/National Doctorate/2016-21160819) and Finally, Rodrigo H. Herrera acknowledges the financial support for his $\mathrm{PhD}$ studies from the Scholarship Programme of Conicyt Chile (ANID-PCHA/National Doctorate/201821180884).

\section{REFERENCES}

Alarcón, D. M., Alarcón, I. M., and Alarcón, L. F. 2013. "Social network analysis: A diagnostic tool for information flow in the AEC industry." Proc. $21^{\text {st }}$ Ann. Conf. Int. Group for Lean Construction, 196-205, Fortaleza, Brazil.

Baiden, B. K., Price, A. D. F., and Dainty, A. R. J. 2006. "The extent of team integration within construction projects." International Journal of Project Management, 24(1), 13-23. https://doi.org/10.1016/j.ijproman.2005.05.001

Ballard, G. 1994. "The Last Planner.” Northern California Construction Institute Spring Conference, Monterey, CA.

Diehl, D. 2019. "Language and interaction: applying sociolinguistics to social network analysis." Quality and Quantity 53, 757-774, https://doi-org/10.1007/s11135-0180787-5

Flores, F. 2015. Conversaciones para la Acción: Inculcando una cultura de compromiso en nuestras relaciones de trabajo. (in Spanish) [Conversations for Action and 
Collected Essays: Instilling a Culture of Commitment in Working Relationships], Lemoine Editores.

Flyvbjerg, B. 2006. "Five Misunderstandings About Case-Study Research. Qualitative Inquiry, 12: 219-245.

Helmreich, R. L. 1998. "Error management as organizational strategy." Proc. IATA Human Factors Seminar, 1-7. Austin, Texas.

Herrera, R., Mourgues, C., Alarcón, L. F., and Pellicer, E. 2020. "Understanding interactions between design team members of construction projects using social network analysis." J. Constr. Eng. Manage., 146(6) 04020053 1-13. https://doi.org/10.1061/(ASCE)CO.1943-7862.0001841

Howell, G. A., Macomber, H., Koskela, L., and Draper, J. 2004. "Leadership and Project Management: Time Fora Shift from Fayol to Flores." Proc. $12^{\text {th }}$ Ann. Conf. Int. Group for Lean Construction, 1-8, Helsingør, Denmark.

Humayun, M. and Gang, C. 2013. "An empirical study on improving shared understanding of requirements in GSD." Int. J. Software Engineering and its Applications, 7, 79-92.

Kereri, J., Harper, C. 2019. "Social Networks and Construction Teams: Literature Review”. ASCE, J. Constr. Eng. Manage.,145(4) 03119001 1-10. https://doiorg.pucdechile.idm.oclc.org/10.1061/(ASCE)CO.1943-7862.0001628.

Koskela, L., and Howell, G. A. 2002. "The underlying theory of project management is obsolete." Proc. PMI Research Conference. 293-302. Seattle, Washington.

Phelps, A. F. 2012. "Behavioral factors influencing lean information flow in complex projects." Proc. $20^{\text {th }}$ Ann. Conf. Int. Group for Lean Construction, 1-10, San Diego, CA.

Priven, V., and Sacks, R. 2015. "Effects of the Last Planner System on Social Networks among Construction Trade Crews." ASCE, J. Constr. Eng. Manage., 04013045(11) 111. https://doi.org/10.1061/(ASCE)CO.1943-7862.

Salazar, L. A., Ballard, G., Arroyo, P., and Alarcón, L. F. 2018. "Indicators for Observing Elements of Linguistic Action Perspective in Last Planner® System." Proc. $26^{\text {th }}$ Ann. Conf. Int. Group for Lean Construction, 402-411, Chennai, India. https://doi.org/10.24928/2018/0441.

Salazar, L., Retamal, F., Ballard, G., Arroyo, P., and Alarcón, L. F. 2019. "Results of Indicators from the Linguistic Action Perspective in The Last Planner ${ }^{\circledR}$ System." Proc. $27^{\text {th }}$ Ann. Conf. Int. Group for Lean Construction, 1241-1250, Dublin, Ireland. https://doi.org/10.24928/2019/0148.

Schöttle, A., Haghsheno, S., and Gehbauer, F. 2014. "Defining cooperation and collaboration in the context of lean construction." Proc. 22 $2^{\text {nd }}$ Ann. Conf. Int. Group for Lean Construction: Understanding and Improving Project Based Production, 1269-1280, Oslo, Norway.

Viana, D., Formoso, C. T., and Isatto, E. L. 2011. "Modelling the network of commitments in the last planner system." Lean Construction J., Special Issue, 55-67.

Yacuzzi, E. 2005. "El estudio de caso como metodología de investigación: Teoría, mecanismos causales, validación." (in Spanish) [The case study as a research methodology: Theory, causal mechanisms, validation], CEMA Working Papers: Serie Documentos de Trabajo, N²96 1-37.

Yin, R. K. 2003. "Case Study Research: Design and Methods." SAGE Publications. Thousand Oaks, CA. 